\title{
APPLICATION OF THE FMEA TECHNIQUE IN A PROJECT RISK ANALYSIS
}

\author{
Danijela Toljaga-Nikolić, Marija Todorović, Dragan Bjelica \\ Faculty of Organizational Sciences, University of Belgrade, Serbia
}

\begin{abstract}
Project risk management aims at defining adequate risk response strategies, which includes the prior identification and analysis of project risks. By using techniques such as FMEA (Failure Modes and Effects Analysis) for project risk analysis, it is possible to prevent ineffective and inefficient spending of time and resources in the project, prevent failures and contribute to meeting the project goals and the project success.
\end{abstract}

Key words: Project, risk, project risk analysis, FMEA.

\section{INTRODUCTION}

A project manager devotes special attention to the risk analysis in the project during the process of project preparation and planning. In order for project implementation to begin and take place according to the plan, this analysis should be approached in detail and involve a larger number of stakeholders in order to cover all key segments of the project in which risks can arise. Each organization and individual is characterized by an acceptable level of risk, which also depends on economic and financial resources, technological limitations, individual experiences and management decisions (Bahrami, Bazzaz, \& Sajjadi, 2012). The activities in the project itself are of varying degree of complexity and do not have the same risk exposure. And in a situation where the same or similar project is repeated after a certain time, its activities have different likelihood of occurrence of risk events in relation to the previous project, precisely because of the specifics of each project individually. It can be said that project risk management is critical to the success of the project (Carbone, \& Tippet, 2004). According to Toljaga-Nikolić, Todorović, \& Bjelica (2014), the project manager has to face the possibility of an issue before it occures. By applying appropriate risk management techniques, the project manager will have greater control over project, where the risk management plan should be part of the project management plan.
According to Bahrami, et al., (2012), during the project, the main aim of the project manager is to minimize the risks that the project carries and reduce the costs associated with it. Due to continuous technological innovations, the authors proposed the implementation of FMEA (Failure Modes and Effects Analysis) technique, which represents a system tool that helps the project team to identify, prevent, eliminate and control potential errors which occur in the given system or project. The FMEA technique was introduced by the US military forces in the late 1940s, and intensively entered into use by NASA in 1963 within the Apollo program (Ebeling, 2001) and has been used as a tool for systemic analysis of the safety and reliability of processes and products. Rahimi, TavakkoliMoghaddam, Iranmanesh, \& Vaez-Alaei (2018) stated that project risks might lead to significant failures and disturb fulfilling of project's goals, therefore it is important to identify, evaluate, and control the problem effectively.

Today, this technique is applicable in many areas, although at the beginning it was typical for analysis within nuclear plants, and then applied in the automotive industry (mid-1970s Ford, Toyota, 1980s Peugeot). Wetterneck, Skibinski, Schroeder, Roberts, \& Carayon (2004) emphasize that the FMEA technique is used to identify, analyze and eliminate certain and / or potential failures, problems and causes of errors in systems, designs, processes and / or services. Although initially perhaps not noticeable, these errors can cause catastrophic 
consequences in the systems, and the techniques themselves help in their reduction or elimination. The FMEA technique helps to identify and overcome weak points in the early stages of developing the concepts of products and services (Plaza, Ube, Medrano, \& Blesa, 2003). In order to identify and analyze potential errors, each component of the process, product or service needs to be analyzed individually. The main aim is to reduce the probability of errors and reduce the impact on the process or completely eliminate it.

\section{APPLICATION OF FMEA TECHNIQUE IN DIFFERENT AREAS}

FMEA is a technique that is applied in a many different areas. Garayoa, Vitas, Diez-Leturia, \& Garcia-Jalon (2011) and Legnani, Leoni, Berveglieri, Mirolo, \& Alvaro (2004) believe that, although the HACCP system is compulsory in the food industry, food safety mistakes are often happening. Trafialek, \& Kolanowski (2014) point to the importance of the application of the FMEA technique in order to identify areas where the risk of food safety is growing within the implementation of the HACCP system. They state that the application of the technique in the verification process in the HACCP system can have a major impact on a food safety. Arvanitoyannis, \& Varzakas (2008) showed through the case study the application of the FMEA technique in the salmon processing industry. Processes in meat processing with the highest values of RPN number were identified and after the application of appropriate measures, the new calculation of RPN values showed lower values and thus the benefit of the application of the technique. Greenall, Walsh, \& Wichman (2007) believe that FMEA technique can be successfully applied in pharmaceutical practice and in the field of health care. It not only helps in identifying possible errors and consequences, it is also the basis for developing strategies for improvement. According to the authors, this area is characterized by high-risk processes, by complexity, lack of standardization and largely included human factor. In the food industry it is also possible to apply the technique in order to ensure the production of quality products and improve processes in the production cycle (Scipioni, Saccarola, Centazzo, \& Arena,
2002). Cheng, Yen, Wong, \& Ho (2008) propose the use of FMEA engineering techniques to analyze the risk of contamination in residential buildings of Asian cities due to contamination in their joint drainage systems.

\section{APPLICATION OF FMEA TECHNIQUE IN PROJECT RISK MANAGEMENT}

\subsection{Characteristics of FMEA techniques}

During the preparation of the project realization, one of the key analysis is the analysis of project risks, with the aim to identify preventive measures and possibilities for improvement during the project preparation phase. The FMEA technique is characterized by a proactive action orientation, as opposed to a reactive, which means that the purpose of applying this technique is to detect how to prevent unwanted situations, rather than how to eliminate them if they occur. Using techniques such as FMEA can prevent inefficient spending of time and resources in the project, prevent failures and contribute to the success of meeting project goals. FMEA is a set of activities to identify and evaluate possible product or process errors and the consequences of these errors, and then suggest activities that can reduce or eliminate the likelihood of these errors (Bahrami, et al., 2012). Szmel, \& Wawrzyniak (2017) identified the method as an important element of safety management process and as safety analysis method.

In order to carry out risk identification and assessment in the project, it is necessary to have complete and relevant information for all project processes and activities, their characteristics and the resources involved in the implementation. Causes of risk occurrence should not be sought only within the processes and activities, but also in the project environment and stakeholders. It is therefore important to involve individuals who have knowledge and experience regarding the project, but also use knowledge from previous projects, lessons learned, documents and all available resources that can be helpful in order to get a list of potential risk events. A detailed description of the project, all phases and activities is required, the implementation of the WBS diagram, in order to have an insight into the logical connection. The next step is 
identifying the risks associated with each project segment and predicting the impact on the project that would have their occurrence. It can be said that this technique requires a lot of time and input information.

The purpose of the application of the technique is to reduce the likelihood of occurrence of risks in the phases of the project and to reduce the impact on the project or completely eliminate it. According to Madoxx (2005) and Sankar, \& Prabhu (2001), three parameters are important for the analysis: the impact or severity of the consequence of risk ( $\mathrm{S}$ Severity), the likelihood of occurrence of risk (O-Occurrence) and the existence of capacities for identifying possible risk rates (D-Detect).
By multiplying these three parameters, the RPN (Risk Priority Number) size is obtained, which represents the numerical risk assessment assigned to the project phase and its value ranges from 1 to 1000 .

$$
\mathrm{RPN}=(\mathrm{S}) \times(\mathrm{O}) \times(\mathrm{D})
$$

The degree of seriousness of risk is reflected in the effects it exerts if it occurs (Bahrami, et al., 2012). By making changes in the process itself and the way in which activities are carried out, it is possible to influence the reduction of this degree. Sankar, \& Prabhu (2001) propose the quantification of the degree of risk severity using the scale from 1 to 10 (Table 1), where the effects are described qualitatively.

Table 1: Ranking of risk according to the severity of its effects (Sankar \& Prabhu, 2001)

\begin{tabular}{|c|c|}
\hline Rank & Effects \\
\hline 10 & Critical \\
\hline 9 & Serious \\
\hline 8 & Extreme \\
\hline 7 & Big \\
\hline 6 & Significant \\
\hline 5 & Moderate \\
\hline 4 & Low \\
\hline 3 & Small \\
\hline 2 & Very small \\
\hline 1 & No effect \\
\hline
\end{tabular}

According to (Trammell, Lorenzo, \& Davis, 2004) and (Sankar, \& Prabhu, 2001), FMEA implies an analysis of each component of the system, which may be long-lasting but necessary to detect potential risk occurrence (Table 2) and assess the probability of occurrence (Table 3 ).
The probability of occurrence of risk is about the frequency with which the potential risk can occur. In order to assess this, it is necessary to know the cause, that is the driving mechanism. According to Sankar \& Prabhu( 2001), the likelihood of risk occurrence can be ranked on a scale of 1 to 10 based on values that determine this probability, as shown in Table 3.

Table 2: Ranking of possibilities for detection of causes of risk (Sankar, \& Prabhu, 2001)

\begin{tabular}{|c|c|}
\hline Rank & Opportunity to discover \\
\hline 10 & Total uncertainty \\
\hline 9 & Very uncertain \\
\hline 8 & Uncertain \\
\hline 7 & Very low \\
\hline 6 & Low \\
\hline 5 & Moderate \\
\hline 4 & Moderately high \\
\hline 3 & High \\
\hline 2 & Very high \\
\hline 1 & Certain \\
\hline
\end{tabular}


Table 3: Ranking of the frequency and likelihood of occurrence of risk (Sankar, \& Prabhu, 2001)

\begin{tabular}{|c|c|c|}
\hline Rank & Frequency of occurrence & Probability of occurrence \\
\hline 10 & $>1$ od 2 & $\begin{array}{c}\text { Extremely high, failure is } \\
\text { almost inevitable }\end{array}$ \\
\hline 9 & 1 od 3 & Very high \\
\hline 8 & 1 od 8 & Repeating failures \\
\hline 7 & 1 od 20 & High \\
\hline 6 & 1 od 80 & Moderately high \\
\hline 5 & 1 od 400 & Relatively low \\
\hline 4 & 1 od 2000 & Negligible \\
\hline 3 & 1 od 15000 & Almost impossible \\
\hline 2 & 1 od 150000 & \\
\hline 1 & $<1$ od 1500000 &
\end{tabular}

The frequency of failure or pre-estimated error can be reduced by the impact on the cause or mechanism that triggers this risk. That is why the importance of FMEA application in its preventive role is given, since it is possible to timely introduce changes to the project plan and documentation, thus reducing the frequency of errors and failure. The application of the technique at the design stage helps to avoid the emergence of risk, and implementation in the implementation phase helps in the process of control. Project risk management is a complex area of project management and requires the investment of time, knowledge, experience and other resources. With the application of the FMEA technique, the basis for prioritization of potential risks in the project is obtained.

Activities in the process of application of the FMEA technique are given in Figure 1 (Bahrami, et al., 2012). 


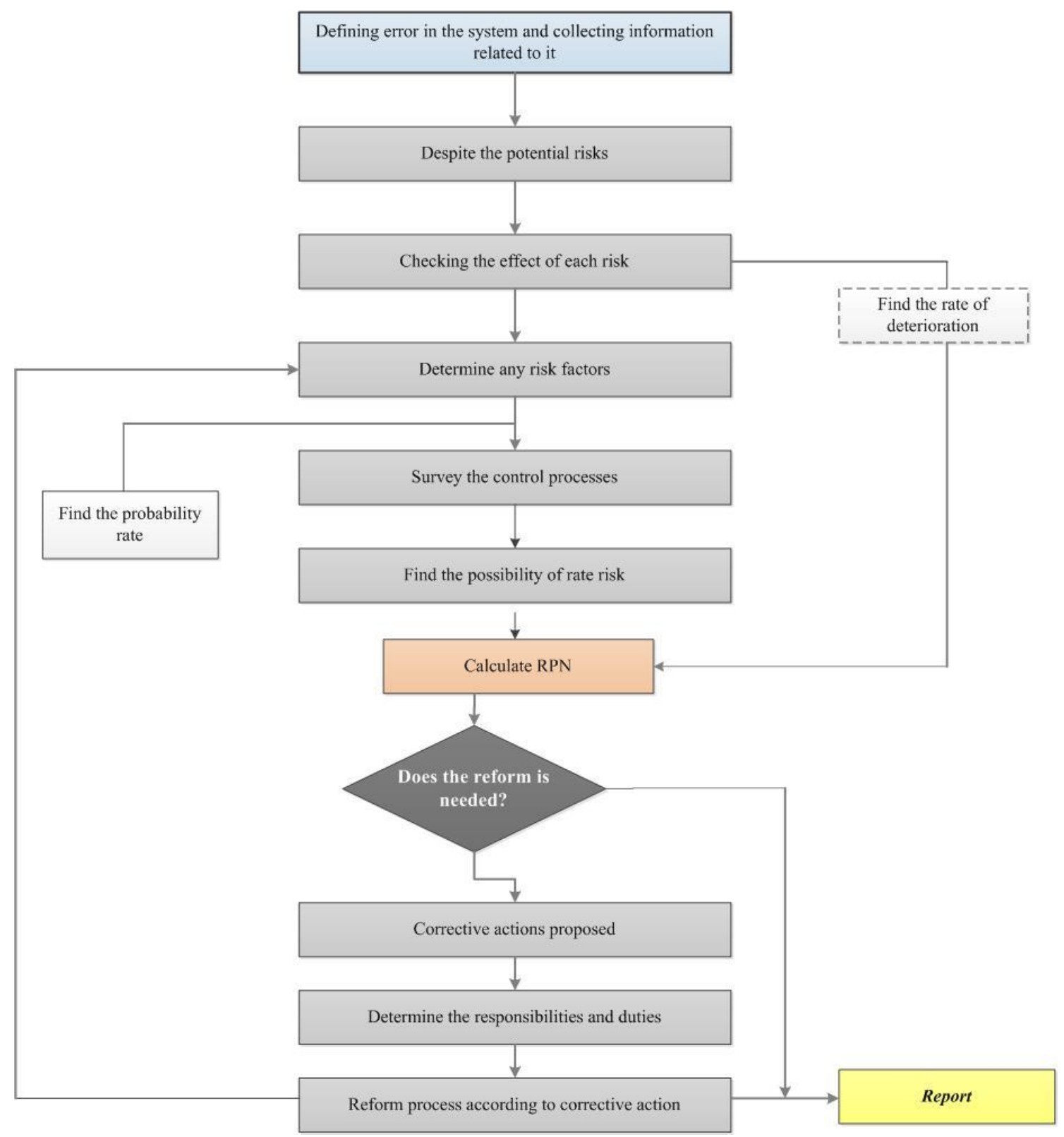

Figure 1: Cycle of application of FMEA technique in a project risk analysis

(Bahrami, et al., 2012)

The considered risks are ranked according to the RPN value calculated using the formula (1). Risks with a higher RPN value are considered more critical and will have priority in additional analysis and resource allocation. The purpose of the application of the technique is preventive action and making improvements in the project documentation, as well as the investing of additional resources, in order to eliminate the possibility of occurrence of risk or mitigate its effects. It is possible, through the process and activities revision and resources allocation in the project, to eliminate the causes of potential risks that have been the subject of FMEA analysis. This requires the investing of additional time and resources, but the benefit is higher, since after these actions, the identified risk is expected not to be occured during project implementation.

\section{DISADVANTAGES OF FMEA TECHNIQUE}

FMEA technique ranks risks exclusively by the value of RPN number, which can be a trigger for criticizing this technique. Sankar, \& Prabhu (2001) state that the values of the parameters within the structure of the RPN number are unreasonably ignored and only its final value is observed. For example, it is possible to ignore 
the risks that have a lower value of RPN, but in its structure, the high likelihood of risk occurrence or the severity of the effect (Bahrami, et al., 2012). If the severity of the potential risk effect is estimated at 10 , and the likelihood of occurrence with 1 and the possibility of detection also with 1 , the calculated RPN value will be 10 , which will not place this risk in those that the project manager should deal with, since it will not be highly ranked. However, its occurrence would be catastrophic for the system and therefore its causes must be investigated and appropriate measures have to be prepared.

\section{CONCLUSION}

Each project has its specifics where its activities have different likelihood of occurrence of risk events. For a project manager it is important to minimize the risks that the project carries and reduce the costs associated with it. Technique that can help a project team to identify, prevent, eliminate and control potential errors that occur in the given project is the FMEA (Failure Modes and Effects Analysis). This technique is applicable in different areas. It contains a set of activities for identifying and evaluating possible errors and the consequences of these errors within the project activities. After that it is possible to suggest activities that can reduce or eliminate the likelihood of these errors.

\section{Acknowledgments}

This paper is the result of the project of basic research "Exploring modern trends of strategic management of the application of specialized management disciplines in the function of the competitiveness of Serbian economy", no. 179081, funded by Ministry of education, science and technological development of the Republic of Serbia.

\section{REFERENCES}

Arvanitoyannis, I., \& Varzakas, T. (2008). Application of ISO 22000 and Failure Mode and Effect Analysis (FMEA) for industrial processing of salmon: A case study. Critical Reviews in Food Science and Nutrition, 48(5), 411-429. doi:10.1080/10408390701424410
Bahrami, M., Bazzaz, D., \& Sajjadi, S. (2012). Innovation and Improvements In Project Implementation and Management Using FMEA Technique. Procedia - Social and Behavioral Sciences, 41, 418-425. doi:10.1016/j.sbspro.2012.04.050

Carbone, T., \& Tippet, D. (2004). Project risk management using the project risk FMEA. Engineering Management Journal, 16(4), 28-35.

doi:10.1080/10429247.2004.11415263

Cheng, C., Yen, C., Wong, L., \& Ho, K. (2008). An evaluation tool of infection risk analysis for drainage systems in highrise residential buildings. Building Service Engineering Research and Technology, 29(3), 233-248. doi: $10.1177 / 0143624408091448$

Ebeling, C. (2001). An introduction to reliability and maintainabillity engineering. New Delhi: Tata McGrewHill.

Garayoa, R., Vitas, A., Diez-Leturia, M., \& Garcia-Jalon, I. (2011). Food safety and the contact catering companies: food handlers, facilities and HACCP evaluation. Food control, 22, 2006-2012. doi:10.1016/j.foodcont.2011.05.021

Greenall, J., Walsh, D., \& Wichman, K. (2007). Failure mode and effects analysis: A tool for identifying risk in community pharmacies. CPJ/RPC, 140(3), 191-193. doi:10.1177/171516350714000324

Legnani, P., Leoni, E., Berveglieri, M., Mirolo, G., \& Alvaro, N. (2004). Hygienic control of mass catering establishments, microbiological monitoring of food and equipment. Food control, 15(3), 205-211. doi:10.1016/S0956-7135(03)00048-3

Madoxx, M. (2005). "Error apparent". Industrial Engineer, Vol.37, No.5 , 40-44.

Plaza, I., Ube, M., Medrano, M., \& Blesa, A. (2003). Application of the Philosophy of Quality in the Digital Electronic Matter. International Conference on Engineering Education. Valencia, Spain.

Rahimi, Y., Tavakkoli-Moghaddam, R., Iranmanesh, S. H., \& Vaez-Alaei, M. (2018). Hybrid Approach to Construction Project Risk Management with Simultaneous FMEA/ISO 31000/Evolutionary Algorithms: Empirical Optimization Study. Journal of 


\section{Construction Engineering and}

Management, 144(6).

doi:10.1061/(ASCE)CO.1943-

7862.0001486

Sankar, N., \& Prabhu, B. (2001). Modified approach for prioritization of failure in a system failure mode and effects analysis. International Journal of Quality \& Reliability Management, 18(3), 324-335. doi:10.1108/02656710110383737

Scipioni, A., Saccarola, G., Centazzo, A., \& Arena, F. (2002). FMEA methodology design, implementation and integration with HACCP system in a food company. Food Control, 13(8), 495-501. doi:10.1016/S0956-7135(02)00029-4

Szmel, D., \& Wawrzyniak, D. (2017). Application of FMEA method in railway signalling projects. Journal of KONBiN, 42(1), 93-110. doi:10.1515/jok-20170020

Toljaga-Nikolić, D., Todorović, M., \& Bjelica, D. (2014). Risk management methods: How to deal with risks in a project? XIV
International Symposium - Symorg 2014 "New business models and sustainable competitiveness". Zlatibor, Serbia: Faculty of Organizational Sciences.

Trafialek, J., \& Kolanowski, W. (2014). Application of Failure Mode and Effect Analysis (FMEA) for audit of HACCP system. Food Control, 44, 35-44. doi:10.1016/j.foodcont.2014.03.036

Trammell, S., Lorenzo, D., \& Davis, B. (2004). Integrated hazard analysis: using the strengths of multiple methods to maximize the effectiveness. Professional Safety, 49(5), 29-37.

Wetterneck, T., Skibinski, K., Schroeder, M., Roberts, T., \& Carayon, P. (2004). Challenges with the performance of failure mode and effects analysis in healthcare organizations. PROCEEDINGS of the HUMAN FACTORS AND ERGONOMICS SOCIETY 48th ANNUAL MEETING, 1708-1712. 